\title{
Perioperative Management for Surgical Repair of Ebstein's Anomaly
}

\author{
Marsela Goga*, Saimir Kuci, Alfred Ibrahimi, Ervin Bejko, Stavri Llazo, Ermal Likaj, Jacob Zeitani
}

Received: 05 June 2021 / Accepted: 29 June 2021 / Published online: 20 July 2021

This article is published with open access at $\underline{h t t p s: / / j o u r n a l . a s t e s . o r g . a l}$

(C) The author(s) 2021. \& Copyright (C) 2021, the Albanian Society for Trauma and Emergency Surgery

(a) The Albanian Journal of Trauma and Emergency Surgery is an Open Access Journal. All articles are distributed under the terms of the Creative Commons Attribution Non-Commercial License: http://creativecommons.org/licenses/by-nc/4.0/) which permits unrestricted non-commercial use, distribution, and reproduction in any medium provided the original work is properly cited.

\begin{abstract}
Background: Ebstein's anomaly is a rare and complex heart defect that affects the tricuspid valve and is accountable for around $1 \%$ of congenital cardiac abnormalities. It is one of the most common congenital causes of tricuspid valve regurgitation. Ebstein's anomaly often is diagnosed prenatally, due to its severe cardiomegaly. Some individuals with this anomaly do not experience complications until adulthood and even then, they have mostly minor complaints like exercise intolerance. An atrial septal defect is most commonly (70-90\%) associated with Ebstein's anomaly. However, ventricular septal defect (VSD) can be associated with 2-6\% of the cases.

Case presentation: This report presents a case of surgical intervention for a 38-year-old female with Ebstein's anomaly symptomatic with moderate-severe pulmonary regurgitation and foramen ovale apertum.

Conclusions: Ebstein anomaly is a complicated form of congenital heart disease with variable clinical presentations. The anesthetic plan must also focus on maintenance of RV function and avoidance of increase in PVR. Reversible causes of increased PVR, such as acidemia, hypoxemia, and hypercarbia must be avoided. Agents that lower PVR, such as nitrates, and nitric oxide may be beneficial in patients with severe pulmonary hypertension.

With a sound knowledge of the cardiac anatomy, accurate scheming of surgical outcomes, routine follow-ups, multidisciplinary team approach, and better management, an experienced center can ultimately improve the prognosis of such patients.

Keywords: Ebstein's anomaly (EA), tricuspid valve (TV), arrhythmias

Abbreviations: PVR - Pulmonary Vascular Resistance; CPB - Cardio Pulmonary Bypass; EA-Ebstain Anomaly; RV-Right Ventricle; RA - Right Atrium; ASD - Atrial Septal Defect; TEE - Transesophageal Echocardiography; TVR - Tricuspid Valve Regurgitation; MVR - Mitrale Valve Rigurgitatone; RFA - Radiofrequency Ablation; PAH - Pulmonary Arterial Hypertension; MS - Mitral Stenosis; SVT - Supraventricular Tachycardia; ACP - Accessory Cardiac Pathway
\end{abstract}

\section{Introduction}

Ebstein's anomaly is a disorder that primarily involves the tricuspid valve (TV). The anomaly is named after Wilhelm Ebstein, who in 1866 first described the defect's symptoms on the heart of 19-year-old Joseph Prescher [1].

The EA produces several anatomical variations and is characterized by:

Original article, no submission or publication in advance or in parallel

\section{* Corresponding author:}

Marsela Goga MD

$\bowtie$ marselagoga@hotmail.com

German Hospital International Tirana, ALBANIA
- Embryonic failure of delamination of the septal inferior and anterior leaflets of the TV, resulting in adherence of the leaflets to the underlying right ventricular (RV) myocardium

- Apical displacement of the tricuspid leaflets' annular hinge points (septal $>$ inferior $>$ anterior) with an antero apical shift in the functional TV orifice toward the RV outflow tract

- Dilatation of the arterialized portion of the RV along with anterior leaflet fenestrations, redundancy or tethering and muscularization

- Dilatation of the anatomic TV annulus, thus typically results in severe regurgitation.

Ebstein anomaly's most common symptoms are cyanosis, dyspnea, decreased exercise tolerance, tachycardia, chest pain, and syncope. Arrhythmias are common as well and include accessory conduction pathways 
(Wolff-Parkinson-White syndrome) in about $15-20 \%$ of the defected ones and around $30-40 \%$ of those affected patients will develop atrial tachyarrhythmias by age 50 . Other commonly associated cardiac defects include atrial septal defect or patent foramen ovale (70-90\%), ventricular septal defect (2-6\%), and RV outflow tract obstruction that can occur as a secondary to structural abnormalities (pulmonary valve stenosis or pulmonary atresia), branch pulmonary artery stenosis or patent ductus arteriosus. In cases where preexcitation is present (Wolff- ParkinsonWhite syndrome), preoperative electrophysiologic study and ablation usually are recommended at age of 4 to 5 years and typically followed by surgical repair of the anomaly.

Surgery includes symptoms like fatigue, decreased exercise tolerance, cyanosis and shortness of breath or progressive RV enlargement, RV dysfunction, or the onset of atrial tachyarrhythmias. Operative management routinely consists of TV repair or replacement, selective plication of the aRV, right reduction atrioplasty, closure (or subtotal closure) of any atrial septal communications, and correction of other associated anomalies.

\section{Case Report}

Patient S.O. 38 years old, mother of 2 children with body weight $45 \mathrm{~kg}$ and BMI $18.75 \mathrm{~kg} / \mathrm{m} 2$ was presented to the hospital with complaints such as vertigo, episodes of lipotomy and difficulty breathing in eforts, symptoms which have been intensifying especially in the last two years, IKK NYHA 3. Patient without concomitant disease, without chronic drug therapy with laboratory examinations within the normal range. An ECG shows incomplete RBB, sinus rhythm without repolarization disorders. Has performed echocardiography where it results: Arterialization of the right ventricle in the field of Ebstein Anomaly. RA with surface $45 \mathrm{~cm} 2$, RV small with volume $38 \mathrm{ml}$. The leaves of the tricuspid valve are thick, myxomatous and with no coaptation. Moderate tricuspid regurgitation. Tricuspid ring about 52-54 mm. Stored RV function. TAPSE about $16 \mathrm{~mm}$. PsAP $35 \mathrm{mmHg}$. Aneurismatic IAS probable foramen ovale apertum. (Fig.1,2) This case was discussed in the heart team meeting, and we decided to perform an elective surgery for correcting the abnormalities presented.

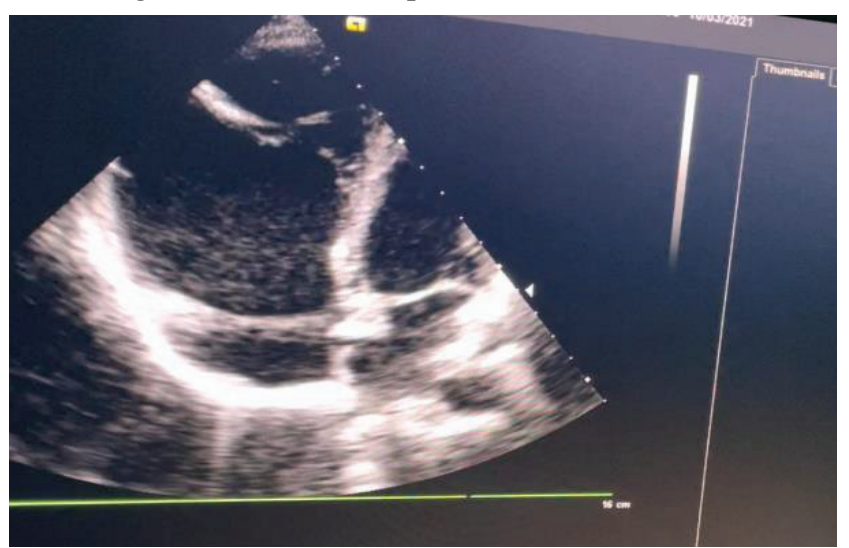

Figure 1 Atrialization of the right ventricle

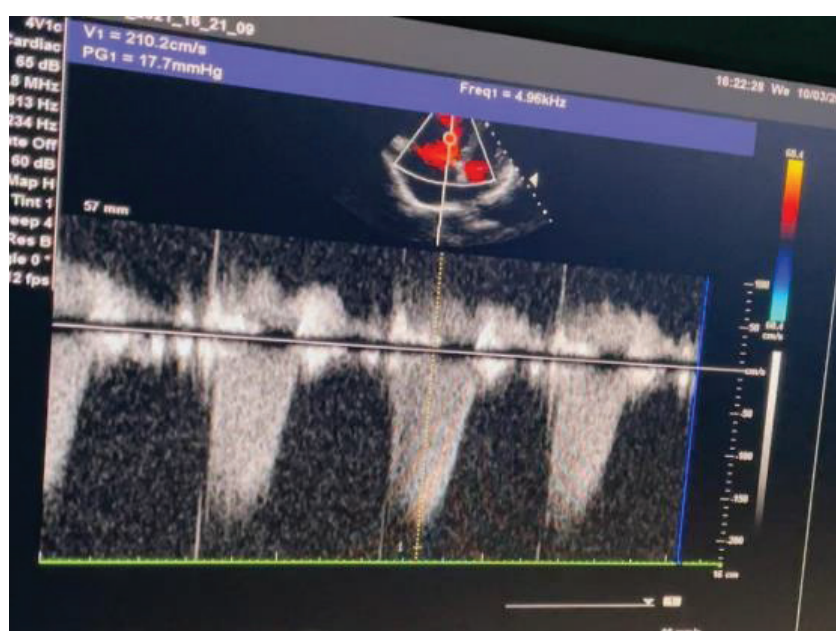

Figure 2 Moderate tricuspid regurgitation

\section{Perioperative management}

The patient was prepared for standard open-heart surgery. All emergency equipment and drugs were made available, including the DC shock machine, although we did not use it, and antiarrhythmic drugs (amiodarone and adenosine). On arrival in the operation room, the patient was in semi reclining position with cyanosis. Initial hemodynamic statuses were blood pressure $110 / 70 \mathrm{mmHg}$, heart rate 75 beats/min, pulse oximetry $90 \%$.

Routine monitors were applied (ECG, $\mathrm{SpO}_{2}$, a right radial arterial line was also inserted for sampling and monitoring arterial blood pressure). Following preoxygenation with a face mask, induction was carried out using propofol $100 \mathrm{mg}$, midazolam (3 mg), fentanyl (100 $\mu \mathrm{g}$ ), and pancuronium ( $4 \mathrm{mg}$ ). Endotracheal intubation and mechanical ventilation were commenced. Central venous access was gained through the right internal jugular veins. Anesthesia was maintained with propofol fentanyl and sevoflurane.

Cardiopulmonary bypass was established by standard aorto bicaval cannulation. Before instituting cardiopulmonary bypass (CPB), total body heparinization was achieved using $300 \mathrm{UI} / \mathrm{kg}$ of heparin. The CPB technique included the use of a membrane oxygenator. CPB flow was maintained at 2.2-2.4 $1 / \mathrm{min} / \mathrm{m}^{2}$, keeping the mean blood pressure at $50-60 \mathrm{mmHg}$ in temperature $35^{\circ} \mathrm{C}$. Myocardial protection was initiated using antegrade blood cardioplegia. The total cross-clamp time was $42 \mathrm{~min}$ and bypass time was $65 \mathrm{~min}$.

Opening of the right atrium native tricuspid valve revealed severe distortion (Fig 3). FOA was found and closed. Arterialized RV was plicated. The tricuspid valve was replaced with $33 \mathrm{~mm}$ biologic SJM Heart Valve (Fig.4). RA tomy wound was closed. 


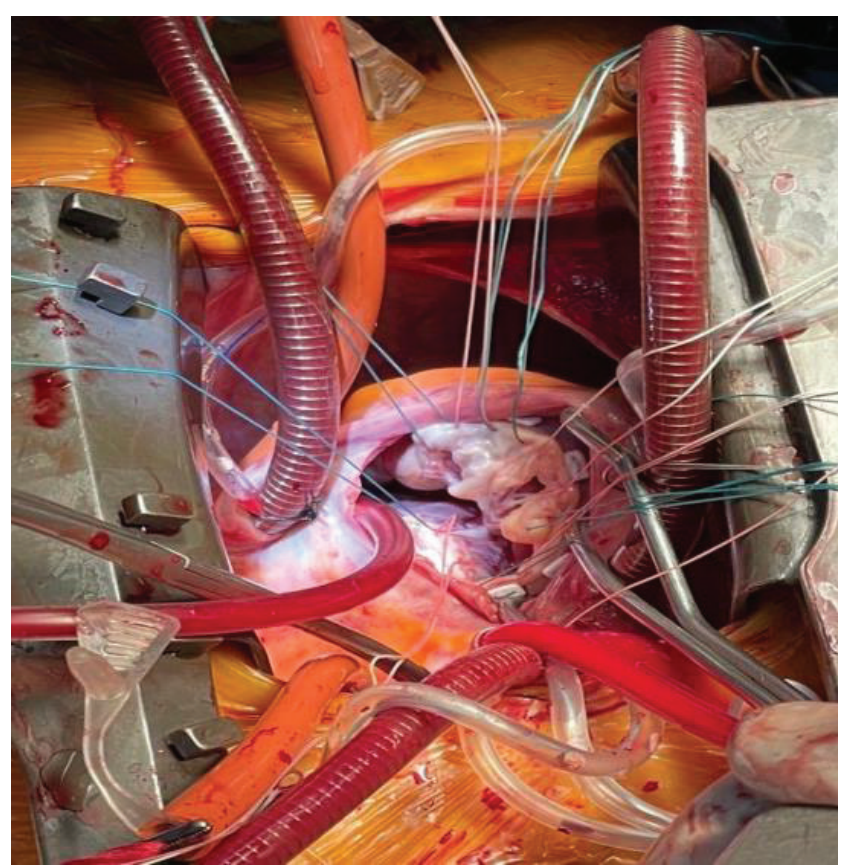

Figure 3. Plication of RA.

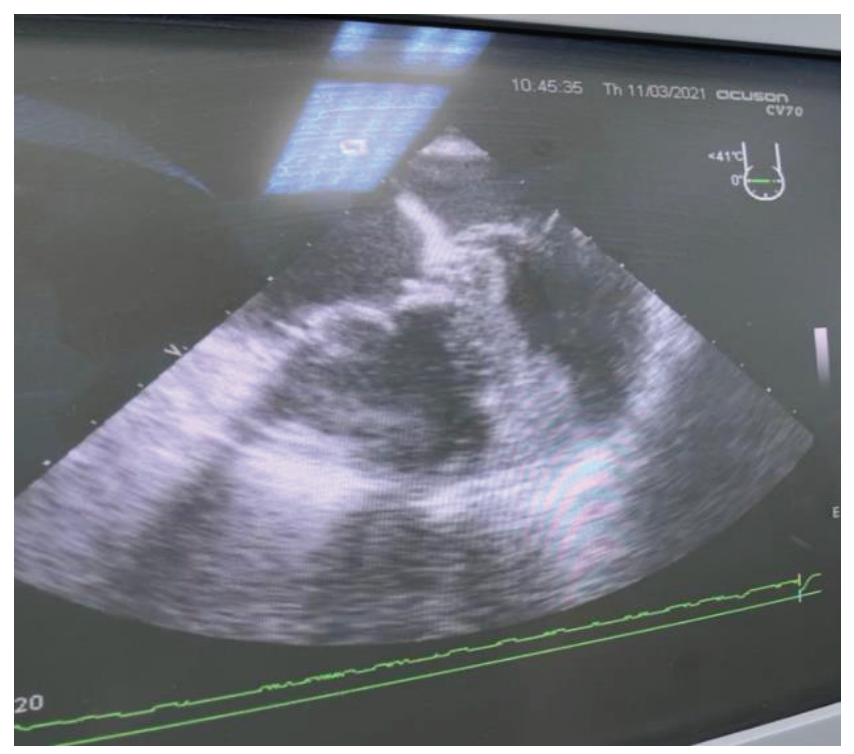

Figure 4 Biologic SJM prosthesis in tricuspid position

After the removal of the cross clamp, the heart started to beat regularly, not followed by arythmias. Separation from the CPB circuit was accomplished using only adrenaline $(0.1 \mu \mathrm{cg} / \mathrm{kg} / \mathrm{min})$, and nitroglicerine $(0.75 \mu \mathrm{cg} / \mathrm{kg} / \mathrm{min})$.

Surprisingly, postoperative ECG the sinus rhythm was maintained at 90 beats/min for the subsequent 3 days after surgery.

The patient was extubated 2 hours later. The patient maintained stable hemodynamics and favorable arterial blood gas levels over the postoperative period while in the intensive care unit, with gradual weaning from inotropic support under adrenaline over the following 2 days. She was transferred to an ordinary ward for 2 days and was discharged from the hospital 5 days after surgery.
Postoperative echocardiography showed a very minimal residual tricuspid regurge with a well-functioning right ventricle. The systolic pulmonary artery pressure dropped to normal range.

\section{Discussion}

TR imposes volume overload of both RA and RV leading to dilatation of RA and functional impairment of small RV. The functional impairment of RV is also determined by ratio of the combined area of RA and atrialized RV relative to area of functional RV, as the atrialized RV either behaves passively during the cardiac cycle or, as an aneurysm that expands paradoxically during systole. $[1,2]$ The presence of an ASD would be helpful in patients with EA, as it would vent the blood to the left side of heart. Thus maintaining the cardiac output but at the expense of increase in cyanosis. With coexisting MS; ASD may not help in maintaining cardiac output. Pulmonary artery pressure is often normal in EA [3].

Coexisting critical MS can modify the natural history of EA by increasing left atrial (LA) pressure that may lead either to bidirectional shunt or, left to right shunt across ASD aggravating RA volume over load. Combination of Ebstein's with MS results in early onset of complications such as development of atrial fibrillation and heart failure. Elevated LA pressure is also transmitted to pulmonary venous system, which lead to early onset of pulmonary arterial hypertension (PAH). PAH causes worsening of TR and early RV failure. Depending on size of ASD (if small) pulmonary edema may develop [4].

Tachyarrhythmic sudden death is a threat regardless of severity of EA [5]. SVT are most common arrhythmia. Although ventricular arrhythmias are uncommon, stimulation of arrhythmogenic atrialized RV may initiate polymorphic ventricular tachycardia or, fibrillation. Therefore, one should avoid stimulation of heart during insertion of central venous catheter. In combination of Ebstein's with MS, atrial flutter or fibrillation with accelerated conduction via ACP may induce fast ventricular rate leading to precipitous increase in pulmonary venous pressure. Therefore, tachyarrhythmia should be treated aggressively and ventricular rate should be controlled between 70 to 90 per minute [6]. Preoperative electrophysiological evaluation is often warranted to locate ACP and possible RFA to avoid recurrent arrhythmia and instability in the perioperative period. RFA prior to surgery is therefore recommended [7]. However, in our case ACP could not be ablated because of poor signal.

Surgical division of ACP may be considered as an option for selected patients [8]. This was not done in our patient because of parahisian location of ACP and fact that surgical repair of EA itself, may reduce the incidence of arrhythmias postoperatively [9]. We preferred to do Danielson repair of TV and MVR. Danielson repair consists of reconstruction of enlarged anterior leaflet into a competent monocusp valve, transverse plication of atrialized RV, excision of redundant atrial free wall and closer of the associated ASD [10]. 
Transesophageal echocardiography (TEE) is an important monitoring modality in these patients. It provides real time information of RV and LV function, degree of TR or stenosis and atrial shunt. Before terminating CPB, it helps in proper deairing of heart. In immediate post bypass periode it allows assessment of repaired tricuspid leaflet function, adequacy of closer of ASD, paravalvular leak and adequacy of function of prosthetic mitral valve. TEE also helps in preload optimization and assessment of postoperative RV and LV function thus guiding use of inotropes. However, we did not use TEE in this case because of its unavailability in OR.

Patients may benefit with light premedication to avoid anxiety induced tachycardia; over sedation at the same time should be avoided to prevent increase in PVR. Anesthetic agent used should not cause significant chronotropic effect or, decrease in refractory period of In EA, enlarged RA together with TR causes pooling of blood in the RA which may delay onset of effect of intravenously administered drugs $[11,12]$. Furthermore, this delay can lead to administration of much higher dose of medication [13]. The pooled blood also act as depot, releasing administered medication subsequently, that may have profound hemodynamic effects, requiring care in dosing and patience during induction of anesthesia. However same may not be seen in cases without massive enlargement of RA and associated large ASD, which may shunt intravenous anesthetic agent to systemic circulation and enhance the onset of action of the intravenous anesthetic agents [13]. If hypotension occurs following induction of anesthesia the initial treatment should consist of intravascular volume and phenylephrine rather than a chronotropic agent. Care must also be taken to prevent the intravenous injection of air or debris, which could produce a paradoxical embolus as patent foramen ovale or ASD is almost invariably present with EA. In patient of EA with coexisting MS, increase in afterload is poorly tolerated due to limited preload reserve together with depressed LV systolic function. So any increase in afterload should be avoided.

The anesthetic plan must also focus on maintenance of RV function and avoidance of increase in PVR. Reversible causes of increased PVR, such as acidemia, hypoxemia, and hypercarbia must be avoided. Agents that lower PVR, such as nitrates, and nitric oxide may be beneficial in patients with severe pulmonary hypertension. Because of small and impaired RV function in EA inotropes may be required both before and after CPB. When choosing an inotrope, agents without significant alpha-agonistic effect, such as phosphodiesterase inhibitors (milrinone) are probably the first choice because of their beneficial effects on PVR. Using a pure beta-agonistic inotropic agent, such as dobutamine, though will have beneficial effect on PVR, but the potential for induction of cardiac arrhythmia; caution should be exercised in its use. We used mild dose of adrenaline to have almost pure beta-agonist action without causing significant increase in heart rate, for weaning from CPB [14].
Mortality after cardiac surgery for Ebstein's anomaly ranges from $2.5 \%$ to $31 \%$. Independent predictors for mortality and morbidity remain poorly defined because of the low incidence of this congenital anomaly. To identify potentially modifiable factors, this retrospective study investigates the prognostic value of perioperative variables for mortality and morbidity.

\section{Conclusion}

Ebstein anomaly is a complicated form of congenital heart disease with variable clinical presentations. The anaesthetic plan must also focus on maintenance of RV function and avoidance of increase in PVR. Reversible causes of increased PVR, such as acidemia, hypoxemia, and hypercarbia must be avoided. Agents that lower PVR, such as nitrates, and nitric oxide may be beneficial in patients with severe pulmonary hypertension.

With a sound knowledge of the cardiac anatomy, accurate scheming of surgical outcomes, routine follow ups, multidisciplinary team approach and better management, an experienced center can ultimately improve the prognosis of such patients.

COI Statement: This paper has not been submitted in parallel. It has not been presented fully or partially at a meeting or podium or congress. It has not been published nor submitted for consideration beforehand.

This research received no specific grant from any funding agency in the public, commercial, or non-profit sectors. There are no relevant or minor financial relationships from authors, their relatives or next of kin with external companies.

Disclosure: The authors declared no conflict of interest. No funding was received for this study.

Acknowledgement: We would like to thank medical staff of Department of Anaesthesiology and Reanimation, German Hospital Tirana, ALBANIA.

\section{References}

1. Celermajer DS, Cullen S, Sullivan ID, Spiegelhalter DJ, Wyse RK, Deanfield JE. Outcome in neonates with Ebstein's anomaly. J Am Coll Cardiol 1992; 19: 1041-6

2. Hamaoka K, Onaka M, Tanaka T, Onouchi Z. Congenital ventricular aneurysm and diverticulum in children. Pediatr Cardiol 1987; 8: 169-75.

3. Sealy WC. The cause of the hemodynamic disturbances in Ebstein's anomaly based on observations at operation. Ann Thorac Surg 1979; 27:536-46

4. Reddy S, Sharma R. Ebstein's anomaly of tricuspid valve with rheumatic mitral stenosis. Int J Cardiol 2009; 33: 52-4. 
5. Gentles TL, Calder AL, Clarkson PM, Neutze JM. Predictors of long-term survival with Ebstein's anomaly of the tricuspid valve. Am J Cardiol 1992; 69: 377-81

6. Jayaprasad N, Thomas V, Madhavan S, Rajesh G, Francis J, Venugopal K. A rare association of Ebstein's anomaly of tricuspid valve with rheumatic mitral stenosis. Echocardiography 2007; 24:176

7. Fuster V, Ryden LE, Cannom DS, et al. ACC/AHA/ESC 2006 guidelines for the management of patients with atrial fibrillation: A Report of the American College of Cardiology/American Heart Association Task Force on Practice Guidelines and the European Society of Cardiology Committee for Practice Guidelines (Writing Committee to revise the 2001 guidelines for the management of patients with atrial fibrillation): Developed in collaboration with the European Heart Rhythm Association and the Heart Rhythm Society. Circulation 2006; 114: e257-354.

8. Lazorishinets VV, Glagola MD, Stychinsky AS, Rudenko MN, Knyshov GV. Surgical treatment of WolfParkinson-White syndrome during plastic operations in patients with Ebstein's anomaly. Eur J Cardiothorac Surg 2000; 18: 487-90.
9. Brancaccio G, Chauvaud S, Carpentier A. Pre and Postoperative evaluation of the incidence of arrhythmia in patients undergoing corrective intervention for Ebstein anomaly. Ital Heart J Suppl 2000;1: 1173-9.

10. Danielson GK, Driscoll DJ, Mair DD, Warnes CA, Oliver WC Jr. Operative treatment of Ebstein's anomaly. J Thorac Cardiovasc Surg 1992; 104: 1195-202.

11. Vester EG. Clinical-electrophysiologic effects of magnesium, especially in supraventricular tachycardia. Herz 1997; 22: 40-50.

12. Sharpe MD, Dobkowski WB, Murkin JM, Klein G, Guiraudon G, Yee R. The electrophysiologic effects of volatile anesthetics and sufentanil on the normal atrioventricular conduction system and accessory pathways in Wolff-Parkinson-White syndrome. Anesthesiology 1994; 80: 63-70.

13. Elsten JL, Kim YD, Hanowell ST, Macnamara TE. Prolonged induction with exaggerated chamber enlargement in Ebstein's anomaly. Anesth Analg 1981; 60: 909-10.

14. Butterworth JF 4th, Prielipp RC, Royster RL, et al. Dobutamine increases heart rate more than epinephrine in patients recovering from aortocoronary bypass surgery. J Cardiothoracic Vasc Anesth 1992; 6:535- 41. 